\title{
Competição enquanto representação ideológica no ambiente ferroviário estadunidense: uma historiografia entre 1859 e 1869
}

\author{
ALEXANDRE HOCHMANN BÉHAR ${ }^{1}$ \\ MARCOS GiLSON G. FEITOSA ${ }^{2}$ \\ ${ }^{1}$ Instituto Federal de Educação, Ciência e TeCnologia de Pernambuco (IFPE), Paulista - Pe, Brasil \\ 2 Universidade Federal de Pernambuco (UFPe) / Departamento de Ciências Administrativas, Recife - PE, Brasil
}

\begin{abstract}
Resumo
O conceito de competição carece de melhor definição no campo dos Estudos Organizacionais (EOs). Esse termo é originário da Economia e identificam-se concepções diversas de competição nas teorizações em EOs. A partir de uma perspectiva crítica, a competição pode associar-se a práticas ideológicas de controle e exercício de poder, além de anacronismos. Assim, considerando o caráter sócio-histórico da cognição social e a construção de sentido discursivo, além da referência organizacional moderna ao modelo de organização e gestão ferroviária comercial estadunidense a partir da Guerra de Secessão (1861-1865), este estudo teve por objetivo analisar aproximações ideológicas a dimensões relativas à competição no ambiente ferroviário estadunidense, entre os anos de 1859 e 1869. Assim, apoiados em 128 documentos jornalísticos, adotamos o método do Quebra-Cabeças Conceitual Infinito para propor sentidos associados à competição no ambiente ferroviário por parte dos agentes discursivos da imprensa e dos gestores ferroviários. A análise propõe o uso ideológico do conceito, orientado pelas mudanças ocasionadas pelo conflito e pelos interesses dos atores envolvidos.
\end{abstract}

Palavras-chave: Historiografia. Ideologia. Competição. Guerra de Secessão. Ferrovias estadunidenses.

\section{Competence as an ideological representation of the railroad surrounding the United States: a historiography between 1859 and 1869}

\begin{abstract}
The concept of competition needs better definition in the field of Organizational Studies (OS). Originating in Economics, different conceptions are identified in the theorizations in OS. From a critical perspective, such an occurrence may be associated with the ideological practices of control and exercise of power, as well as anachronisms. Thus, considering the socio-historical character of social cognition and the construction of discursive meaning, in addition to the modern organizational reference to the US railway company from the Civil War, our objective was to analyze ideological approaches to dimensions associated with competition in the US rail environment between 1859 and 1869 . Thus, supported by 128 journalistic documents, we use the Infinite Conceptual Puzzle method to propose meanings associated with competition in the railway environment by discursive agents of the press and railway managers. The analysis presented proposes the ideological use of the concept, guided by the changes caused by the conflict, as well as the interests of the actors involved.
\end{abstract}

Keywords: Historiography. Ideology. Competition. American Civil War. US railways.

\section{Competencia como representación ideológica en el entorno ferroviario estadounidense: una historiografía de 1859 a 1869}

\section{Resumen}

El concepto de competencia necesita una mejor definición en el campo de los Estudios Organizacionales (EO). Esa expresión es originaria de la Economía y se identifican diferentes concepciones de competencia en las teorizaciones de los EO. Desde una perspectiva crítica, tal competencia puede asociarse con prácticas ideológicas de control y ejercicio del poder, además de anacronismos. Por lo tanto, considerando el carácter sociohistórico de la cognición social y la construcción de un significado discursivo, además de la referencia organizativa moderna al modelo de organización y gestión ferroviaria comercial estadounidense a partir de la guerra civil estadounidense, nuestro objetivo fue analizar los enfoques ideológicos de las dimensiones asociadas con la competencia en el entorno ferroviario estadounidense entre los años 1859 y 1869. Así, con el apoyo de 128 documentos periodísticos, utilizamos el método Infinite Conceptual Puzzle para proponer significados asociados con la competencia en el entorno ferroviario por parte de agentes discursivos de la prensa y los gerentes ferroviarios. El análisis presentado propone el uso ideológico del concepto, guiado por los cambios causados por el conflicto y por los intereses de los actores involucrados.

Palabras clave: Historiografía. Ideología. Competencia. Guerra de Secesión. Ferrovías estadunidenses. 


\section{INTRODUÇÃO}

A elaboração conceitual no campo dos Estudos Organizacionais (EOs) apresenta, historicamente, a incorporação, muitas vezes inadequada, de construções teóricas de diferentes campos de estudo (RAMOS, 1983; MOURA, 2014). Apoiados em anacronismos (MATITZ e VIZEU, 2012; MOURA, 2014; BÉHAR, 2019), os motivos que levam a isso podem associar-se a ideologias orientadas pela manipulação do comportamento individual, a partir dos interesses de grupos específicos (TRAGTENBERG, 2005; BARRETO, 2014; SEIFERT e VIZEU, 2015; BÉHAR, 2019). Desse modo, considerando a importância do conceito de competição nos EOs, assim como as variações nas concepções associadas (BARNEY e HESTERLY, 2009), analisamos neste artigo perspectivas relacionadas à competição, sob uma abordagem histórica e discursiva.

A perspectiva adotada neste estudo foi de que a construção de sentido discursivo se mostra influenciada por condições sócio-históricas que dirigem possiblidades interpretativas da realidade (FOUCAULT, 1999, 2008). Em outras palavras, cada contexto compartilha cognições sociais orientadoras da compreensão individual (VAN DIJK, 1990, 2012). Diante dessas questões, as elaborações discursivas configurariam práticas do exercício do poder em sociedade, sua manutenção ou modificação (FOUCAULT, 1999, 2008; VAN DIJK, 2012), apresentando-se enquanto configurações ideológicas de determinado grupo social para a manipulação de outros grupos, em favor dos próprios interesses (VAN DIJK, 2006, 2012, 2015). Assim, entendemos que interpretações associadas ao conceito de competição tanto decorrem do contexto em que se inserem quanto orientam interpretações e atitudes individuais em sociedade.

Com base nessas concepções, observamos a competição como um conceito originário da Economia e incorporado às diversas concepções teóricas da Administração, sem pretensão de definições específicas. Em seu campo de origem, a noção de competição ascende com o modelo de sociedade burguesa no século XVIII (HOBSBAWM, 2014a, 2014b), especialmente associado às concepções da Escola Clássica da Economia (SMITH, 1976; BACIC, 2011). Percebida como uma espécie de força da natureza, ordenadora das relações comerciais, a competição era considerada um dos pilares dessa nova sociedade (WEBER, 2006; BACIC, 2011), centrada nos ideais de progresso e desenvolvimento humano, em oposição às reminiscências da sociedade medieval (HOBSBAWM, 2014c).

O contexto no qual se desenvolvem tais dimensões sobre a competição está permeado por profundas e amplas mudanças na sociedade europeia. Os nascentes ideais democráticos e individualistas, em conjunto com novas concepções de racionalidade e técnica, inspiraram as ações para a Independência dos Estados Unidos da América (EUA), em 1776 (FERNANDES e MORAIS, 2004; KARNAL, 2004; WEBER, 2006; HOBSBAWM, 2014c). A adoção dos novos ideais europeus de sociedade em sua constituição federativa também se apresenta na perspectiva de magnífica destinação reservada à nova nação. A tal concepção se vinculam, ainda, o avanço territorial (p. ex., com a "Marcha para o Oeste") e o avanço econômico/industrial (FERNANDES e MORAIS, 2004; KARNAL, 2004; AMEUR, 2013). Para atender a tais questões, no contexto do século XIX, as ferrovias tinham importância fundamental (CHANDLER, 1999; PERROW, 2002).

Apontadas como "as primeiras empresas de negócios modernas" (CHANDLER, 1999, p. 81), a atuação dos gestores ferroviários e o uso das ferrovias se mostrou fundamental para a vitória do Norte na Guerra de Secessão (1861-1865). Tal questão alçou definitivamente as ferrovias a um patamar superior dentro e fora do território estadunidense. Internamente, as ferrovias se tornaram o eixo central do desenvolvimento nacional. Estado e empresários se uniram para realizar a construção de uma obra de grande impacto comercial e militar, a primeira ferrovia transcontinental (First Transcontinental Railroad), entre 1862 e 1869. Nesse período, as empresas ferroviárias se apresentavam como modelo organizacional vanguardista diante dos desafios e das oportunidades da época, expandindo-se largamente. Desse modo, tanto o modelo de organização e gestão ferroviária comercial estadunidense como seu uso militar se apresentaram como referências parra outras nações, como a Alemanha e a França (PERROW, 2002; WHITE, 2012; WOLMAR, 2012a, 2012b).

A partir de nossas observações, este artigo tem por objetivo analisar concepções ideológicas da competição no ambiente ferroviário estadunidense entre o período pouco anterior à Guerra de Secessão e a construção da primeira ferrovia transcontinental. A opção por acessar 2 anos anteriores ao conflito decorre da busca por corpus não vinculado ao conflito, no sentido de possibilitar identificação de variação discursiva. Em virtude das características de nosso objetivo de pesquisa, optamos por orientá-la pela perspectiva histórica. Ainda que relativamente recente nos EOs brasileiros, o caráter histórico da análise se vincula à premissa de que construções de significado discursivo decorrem de contextos sócio-históricos específicos, desejando romper com o caráter anacrônico dos EOs (PIERANTI, 2008; COSTA, BARROS e MARTINS, 2010; VIZEU, 2010; MATITZ e VIZEU, 2012). 
Como orientação metodológica, acessamos o Quebra-Cabeças Conceitual Infinito (BÉHAR e FEITOSA, 2019), a partir de documentos originais do período em questão. Tal escolha representa a intenção de realizar uma análise crítico-reflexiva a respeito da orientação ideológica em construções simbólicas, direcionadas a um conceito específico, a partir de uma diversidade de discursos compartilhados socialmente e relacionada a restrito contexto histórico. Como delimitação da pesquisa, escolhemos o periódico American Railroad Journal, em virtude de sua relevância e audiência à época (PERROW, 2002; WHITE, 2012; WOLMAR, 2012a, 2012b), indicando possibilidade de representação e influência do contexto em análise. O corpus compreendeu 128 matérias, selecionadas em 574 edições do jornal, distribuídas em quase 13 mil páginas.

As próximas seções detalham as bases teóricas e metodológicas que orientaram este estudo. Em seguida, apresentamos as impressões decorrentes da análise e, na sequência, as considerações a respeito da pesquisa, além de suas limitações e oportunidades para continuidade.

\section{Discurso e poder na representação do real}

Ao longo do século $\mathrm{XX}$, os estudos relacionados ao discurso ampliaram seu foco analítico, destacando o caráter pragmático das comunicações. A ampliação das perspectivas simbólicas da análise discursiva não se restringiu ao campo da Linguística. Ao contrário, a concepção social atrelada às interpretações do discurso se apresenta como um campo multidisciplinar, vinculado a áreas do conhecimento como Sociologia, Psicologia, Linguística e Filosofia, entre outras (MAINGUENEAU, 2008). Nesse sentido, o aspecto a ser destacado quanto ao papel do discurso na representação de um posicionamento se refere ao proferimento e ao seu caráter proposicional. Assim, pode-se falar em práticas discursivas compartilhadas entre determinados grupos sociais, não apenas no compartilhamento de informações, mas, inclusive, na validação do que, de quem e a quem se pretende comunicar (FOUCAULT, 2008; MAINGUENEAU, 2008).

Enquanto modelo comunicativo, o discurso possibilita interpretações que não se limitam ao texto escrito, mas proporcionam suposições mais amplas, ainda que atreladas a um contexto sócio-histórico específico (FOUCAULT, 2008). Tal questão também é aprofundada por Van Dijk (2006), uma vez que o autor considera fundamental o papel da construção social da linguagem no significado socialmente compartilhado. Alinhado a essa questão, relações de poder entre grupos sociais interfeririam tanto na construção de significados quanto na manutenção ou mudança dos significados compartilhados (VAN DIJK, 2006; FOUCAULT, 2008). A essa questão se associa a concepção crítica de ideologia proposta por Van Dijk $(2006,2015)$.

Para o autor, as ideologias, pautadas pelo eixo discurso-cognição-contexto se apresentariam como modelos de estrutura e organização discursiva dedicada à orientação de práticas sociais, por meio do controle dos modelos mentais subjetivos dos indivíduos. Enquanto prática para o exercício de poder e manipulação, a representação subjetiva da realidade por meio de ideologias tende à polarização das posições, estimulando conflitos e disputas entre o endogrupo (grupo de indivíduos alinhados à ideologia) e o exogrupo (VAN DIJK, 2015). Nessa condição, contexto e discurso se mostram fundamentais na constituição ideológica. No que se refere ao contexto, a importância recai sobre as limitações temporais associadas ao próprio modelo de cognição social, assim como as características comunicacionais associadas ao discurso. Já o discurso se apresenta como o meio pelo qual as ideologias são aprendidas, ou seja, formuladas e disseminadas entre os membros de um grupo. A esse respeito, o discurso ideológico apresenta características estruturais específicas, indicadas pela manipulação discursiva para polarização de posicionamentos, especialmente orientadas por

[...] tópicos positivos sobre NÓS (quão tolerantes, modernos, avançados, pacíficos ou inteligentes NÓS somos), tópicos negativos sobre ELES (quão intolerantes, atrasados, agressivos etc. ELES são), e evitar tópicos negativos sobre NÓS (por exemplo, nosso racismo ou nossa agressão internacional, ou a contribuição dELES para a nossa economia e bem-estar) (VAN DIJK, 2015, p. 56).

Desse modo, Van Dijk $(2006,2015)$ entende que uma análise social da ideologia pressupõe não apenas minucioso exame discursivo (agente discursivo e estrutura), mas detalhada contextualização do ambiente comunicativo (em seus componentes macro e microssociológicos), assim como descrição dos elementos constituintes da cognição social compartilhada no período em análise. Tais aspectos são detalhados nas próximas seções, inclusive os procedimentos metodológicos. 


\section{Concepção econômica da competição e constituição da sociedade estadunidense}

Quanto à perspectiva econômica, a competição está atrelada ao conceito de concorrência perfeita, de modo que "a empresa competitiva é aquela que tem capacidade de concorrer, e esta capacidade decorre de um conjunto de habilidades e condições por ela desenvolvidas ou oferecidas pelo ambiente, e requeridas para o exercício da concorrência" (CARPINTÉRO, 2000, p. 6). Responsável pela dimensão científica atrelada à competição, a escola clássica da Economia "considera a concorrência como força ordenadora que se manifesta no mercado" (BACIC, 2011, p. 24), orientada por uma "mão invisível" (SMITH, 1976, p. 438). Sob tal alicerce, "o progresso econômico e social resulta exclusivamente da iniciativa individual" (GASTALDI, 2005, p. 51). Quanto a essa questão, Bacic (2011, p. 19) entende a "concorrência como fenômeno básico que dirige e outorga sua dinâmica peculiar ao sistema capitalista".

A ascensão dessa concepção não se mostra isolada de um contexto social. Tais considerações denotam uma forma de contestação do modelo medieval e a ascensão da classe burguesa no século XVIII. A esse período se vincula o reforço às novas concepções de racionalidade, liberdade individual e justiça, marcadamente representadas pela Revolução Francesa e pela Revolução Industrial (WEBER, 2006; HOBSBAWM, 2014c).

Fundamental para a consolidação dessa nova sociedade, a Revolução Francesa se apresentou como braço político, objetivando romper com as estruturas estatais tradicionais a partir das premissas de racionalidade, liberdade e justiça (HOBSBAWM, 2014c). Outro marco desse período, a Revolução Industrial viabilizou o desenvolvimento de um novo modelo econômico de produção, sustentado em novas concepções de racionalidade e técnica (WEBER, 2009; HOBSBAWM, 2014c). Atrelada às noções iluministas de racionalidade, progresso e desenvolvimento, a industrialização não limitava as consequências à economia, mas também as relacionava à demonstração do nível de evolução social (DOBB, 2012; HOBSBAWM, 2014c).

O desenrolar desses acontecimentos era acompanhado de perto pelas treze colônias inglesas na América do Norte que apresentam, a partir do século XVII, grande impulso colonizador, ainda que de modo heterogêneo. A esse respeito, Karnal (2004) observa que, enquanto as colônias do Norte apresentavam condições climáticas próximas às de sua metrópole, o que propiciou desenvolvimento de diversidade na produção agrícola, voltada a atender ao mercado interno, o clima das sulistas propiciava o estabelecimento da produção de monocultura para exportação em latifúndios por meio de mão de obra escrava. Assim, os ideais nortistas se desenvolveram de modo independente e em oposição às tentativas de controle do território colonial por parte da coroa inglesa. Tal mobilização ocasiona a declaração de independência do país, em 1776 (KARNAL, 2004; AMEUR, 2013).

Ainda que as diferenças dificultassem uma melhor constituição nacional, "o país, como um todo, permanecia fiel à visão que tinha construído de si mesmo: um lugar independente, democrático e autossuficiente, guiado por pessoas virtuosas que marchavam em direção ao progresso" (FERNANDES e MORAES, 2004, posição 1.634 de 4.675). Entre 1790 e 1860 (AMEUR, 2013), tal noção de grandeza é identificada no crescimento territorial (de 2 milhões de $\mathrm{km}^{2}$ para 8 milhões de km²) e no crescimento populacional (de 4 milhões de habitantes para 31,5 milhões de habitantes).

Contudo, à medida que a nação se fortalecia, as diferenças estruturais entre Norte e Sul entravam em choque e os planos para se tornar uma grande potência mundial eram comprometidos. O estopim da dissolução nacional se dá com a vitória de Abraham Lincoln nas eleições de 1860, colocando frente a frente, em uma batalha interna, os 2 modelos de sociedade (AMEUR, 2013). As consequências da Guerra de Secessão não se limitam a mudanças no cenário político, institucional e social da nação estadunidense, elas se relacionam à consolidação da organização ferroviária enquanto meio para promoção dos ideais de progresso e desenvolvimento. Tal aspecto é detalhado na próxima seção.

\section{Ascensão das organizações ferroviárias e a Guerra de Secessão}

Como observado, o desenvolvimento das organizações e da malha ferroviária estadunidenses se inserem na constituição das bases dessa nação, a partir dos novos princípios sociais compartilhados na Europa. Assim, a dimensão geral associada ao modelo reflete a crença nas organizações para a promoção de progresso social e tecnológico, decorrente das práticas econômicas liberais. A tais aspectos se associam os ideais democráticos, de liberdade individual e justiça, apoiados na nova concepção de racionalidade (WEBER, 2006; HOBSBAWM, 2014b). Vinculam-se a essa realidade características específicas da sociedade estadunidense: a) caráter comercial, apoiado nas bases do que viria a se configurar no capitalismo; b) a diversidade étnica, religiosa e cultural da população; c) o desenvolvimento de um mercado interno desvinculado da metrópole, em virtude do 
desinteresse da coroa inglesa no estabelecimento de um processo colonizador; e d) seu caráter expansionista (FERNANDES e MORAIS, 2004; KARNAL, 2004; AMEUR, 2013).

Nesse cenário, as ferrovias eram percebidas como caminho para o progresso e os impactos tecnológicos, econômicos e sociais decorrentes de suas operações moldaram profundamente a constituição da nação estadunidense. Tal concepção não se refere apenas à consolidação do referido modelo organizacional, mas, inclusive, aos impactos proporcionados pela expansão das ferrovias nas mais variadas atividades produtivas, nas diversas cidades atendidas por suas rotas e sociedades isoladas que passaram a ter rápida conexão com o restante daquele país (CHANDLER, 1963, 1999; PERROW, 2002).

Contudo, ainda que as primeiras locomotivas tenham começado a cruzar o território estadunidense em 1828 (WOLMAR, 2012a), foi a partir da década de 1850 que as ferrovias atingiram os patamares de crescimento e complexidade operacional que demandavam a aplicação de novas tecnologias administrativas (CHANDLER, 1963). O desenvolvimento dessas práticas teria papel primordial na vitória do Norte, na Guerra de Secessão, assim como esse conflito se mostraria crucial para o desenvolvimento dessas organizações e seu modelo gerencial (CHANDLER, 1963; PERROW, 2002; WHITE, 2012; WOLMAR, 2012a, 2012b).

Ainda que a perspectiva relacionada à presença das ferrovias fosse indicativa de desenvolvimento, a estruturação do ambiente ferroviário estadunidense se pautou por práticas competitivas que aceitavam diversas abordagens. Uma que vez o estabelecimento das empresas ferroviárias era orientado pelo mercado (diferentemente da Inglaterra, onde a possibilidade de exploração comercial demandava autorização do Estado), o desenvolvimento da malha ferroviária estadunidense se pautou por disputas intensas e até agressivas. Nesse sentido, não eram incomuns práticas corruptas para a concessão de benefícios junto a representantes políticos locais e sabotagem das linhas de ferro concorrentes. Essa condição perdura até a Guerra de Secessão, mesmo com a aproximação entre as empresas de ferro e as organizações militares (PERROW, 2002; WHITE, 2012; WOLMAR, 2012a, 2012b).

Além de representar a disputa entre os diferentes modelos socioeconômicos praticados no território estadunidense, a Guerra de Secessão se apresenta como o primeiro conflito militar a contar com armamentos e tecnologias oriundos da Revolução Industrial. Assim, o uso das ferrovias pelos estados do Norte potencializou o impacto das inovações bélicas, proporcionando maior flexibilidade às operações militares, assim como sua capacidade de transporte de suprimentos e tropas. Não obstante, o exército nortista contou com importante presença de executivos ferroviários no comando das tropas nortistas, capacitados, na visão das lideranças, para proporcionar uma eficiente gestão do transporte (WOLMAR, 2012a, 2012b).

A identificação das potencialidades militares associadas às ferrovias transformou o modo como o Estado se relacionava com essas organizações. Assim, a partir de maio de 1862, com a assinatura do Ato Presidencial que autorizava a construção da primeira ferrovia transcontinental dos EUA, o papel do governo central passaria a ser de estímulo e fortalecimento do setor ferroviário nacional. Quanto a essa mudança, Perrow (2002), White (2012) e Wolmar (2012a) observam o investimento de grandes montantes financeiros na expansão ferroviária por parte do governo, a constituição de grandes corporações empresariais, com alcance sobre grande parte do território nacional, transportando volumes muito superiores àqueles praticados em período anterior à guerra, além da concentração de poder na imposição das demandas organizacionais diante do Estado. Assim, Wolmar (2012b, posição 1.135 de 6.838, tradução nossa) observa que "de forma geral, a guerra assegurou posição vital para as ferrovias na infraestrutura nacional".

Seguindo essas transformações, a competição entre empresas ferroviárias também atinge novo patamar. Ainda que, anteriormente ao conflito, a competição estivesse restrita à dimensão local ou regional (PERROW, 2002; WHITE, 2012; WOLMAR, 2012a, 2012b), após o conflito, a competição recebe contornos de disputa em nível nacional ou ao menos inter-regional, intensificando as práticas corruptas já ressaltadas e direcionadas a inviabilizar a competição (PERROW, 2002; WHITE, 2012). Nessa nova condição, as empresas ferroviárias passam a ter suas práticas questionadas. A perspectiva compartilhada entre parte da população é de que tais empresários atuariam de modo desonesto, manipulador e autocentrado (WOLMAR, 2012a; WHITE, 2012). Na medida em que a dependência do transporte ferroviário aumentava na sociedade estadunidense, surgiam novos questionamentos quanto a tais práticas, ainda que sua atuação voltada à mudança fosse limitada (WOLMAR, 2012a).

Após esta contextualização sócio-histórica do período, a próxima seção detalha os procedimentos metodológicos adotados para a pesquisa. 


\section{PROCEDIMENTOS METODOLÓGICOS}

Considerando as características deste estudo, orientamos nossa pesquisa sob uma perspectiva histórica, dimensão que vem recebendo maior destaque no campo dos EOs, especialmente aqueles direcionados ao questionamento do mainstream. Tal perspectiva se coloca em oposição ao que é percebido como caráter a-histórico e determinístico de algumas abordagens dos EOs. A relevância de uma análise histórica se coloca não apenas como uma maneira de compor cenários do passado, mas, inclusive (e especialmente), possibilitar novas interpretações de problemas da atualidade (VIZEU, 2010; COSTA, BARROS e MARTINS, 2010).

Assim, a construção do corpus se deu a partir de documentos públicos compartilhados à época. Para tanto, acessamos matérias de um periódico identificado como fórum de destaque no cenário da atividade ferroviária estadunidense ao longo do século XIX: o American Railroad Journal (PERROW, 2002; WHITE, 2012; WOLMAR, 2012a, 2012b). Nesse periódico foram identificadas 163 matérias jornalísticas relacionadas à competição ferroviária, entre os anos de 1859 e 1869, totalizando 574 edições do jornal, em 12.938 páginas. Uma vez que, dentre os atores sociais identificados na análise, apenas os representantes das empresas ferroviárias e da imprensa apresentam volume e continuidade de publicações, nossa análise se dedicou às 128 matérias jornalísticas relacionadas a esses atores.

Como procedimento analítico, apoiamos nossa pesquisa no método Quebra-Cabeças Conceitual Infinito, proposto por Béhar e Feitosa (2019), a partir da História dos Conceitos, de Koselleck $(1992,2006)$ e dos Estudos Críticos do Discurso (ECD), de Van Dijk (2006, 2012). Assim, propõe-se uma análise sincrônica de um conceito, destacando o contexto social a que se vincula (com base nas premissas da História dos Conceitos), direcionada a uma análise crítico-reflexiva de ideologias presentes no discursivo - considerando as relações entre indivíduo, contexto e discurso (com base nas premissas dos ECD) - e dedicada à análise de múltiplos discursos inseridos em um mesmo recorte contextual (BÉHAR e FEITOSA, 2019). Desse modo, são premissas do Quebra-Cabeças Conceitual Infinito: o direcionamento da investigação a uma análise discursiva sincrônica de determinado conceito; a análise por meio de documentos públicos ou privados; documentos estes que representem uma multiplicidade de discursos, sendo discursos que pressuponham construções subjetivas socialmente compartilhadas e historicamente datadas; construções subjetivas que interferem na interpretação e consequente ação individual; interpretação e ação marcadas por relações de poder que sustentam determinada estrutura social e estrutura social identificável pela via discursiva.

Por fim, observamos que a análise, apresentada na próxima seção, foi operacionalizada por meio da análise lexical dos discursos, a partir do que propõe Van Dijk (2006). Assim, orientamos a investigação pela variação dos elementos lexicais no discurso. Como premissa, partimos da consideração de que a escolha lexical se apresentaria como relevante meio para expressão ideológica no discurso. Desse modo, tal análise discursiva é direcionada aos fatores de preposição (adjetivação, complementos e estrutura da oração), coerência local e global (construção de coerência semântica no contexto discursivo) e relações proposicionais (busca pelo que está além daquilo que está escrito) em uma sustentação argumentativa em determinado discurso (VAN DIJK, 2006). Assim, nosso direcionamento foi realizar essas etapas da análise discursiva relativas às concepções de competição no discurso em que tal conceito se encontrava inserido.

\section{Análise discursiva sobre as concepções de competição}

Como observado, a realização da análise proposta resultou na identificação, no corpus em questão, dos atores sociais que com maior constância se posicionaram sobre a competição ferroviária: a) representantes das empresas ferroviárias (72 matérias); e b) representantes da imprensa (56 matérias). Por representantes da imprensa queremos nos referir a matérias jornalísticas do próprio American Railroad Journal ou reproduzidas no periódico em análise, sem autoria individual a partir de outras publicações. Nesse sentido, a escolha pelo conteúdo do periódico é referenciada em Perrow (2002), White (2012) e Wolmar (2012a, 2012b), que destacam sua relevância e audiência à época. Assim, totalizando 128 matérias jornalísticas, daremos prosseguimento à apresentação da análise direcionando nosso recorte por ator social, sendo posteriormente orientada cronologicamente.

A partir da perspectiva dos gestores ferroviários, a noção de competição no ambiente ferroviário pouco se modifica no período em análise. De modo geral, os gestores destacam a competição como algo negativo que precisa ser evitado, o que é visto por Béhar (2018) como uma perspectiva negativa da competição. Em outras palavras, isso significaria dizer que, na visão dos gestores das ferrovias, a competição se mostraria negativa para a sustentação, a ampliação dos negócios e até a 
sobrevivência de suas empresas. A esse respeito, ainda que destoe da noção econômica compartilhada à época, a competição, em período anterior à Guerra de Secessão, é apresentada com adjetivações como "ruinosa", "impolítica", "agressiva", "vigorosa", "desastrosa" ou "maléfica".

A representação dessa perspectiva pode ser ampliada ao observar, em outros trechos, o reforço para acordos no valor de taxas e o desejo de limitação da concorrência (especialmente no que se refere à entrada de novas empresas em trechos considerados saturados). Desse modo, o entendimento compartilhado por esses representantes seria o de combater a competição, como forma de impedir os males a ela associados.

Contudo, no período em que se desenrola a Guerra de Secessão, ainda que a perspectiva relacionada à competição permaneça alinhada a uma noção negativa, observamos alguma alteração da orientação argumentativa. A esse respeito, destacamos maior volume de publicações relacionadas ao estímulo a acordos comerciais e à fusão de empresas ferroviárias, como meios de evitar a competição. A relevância das fusões e dos acordos é especialmente detalhada em 2 matérias apresentadas entre abril e maio de 1863. Em uma delas é retratada uma convenção realizada entre gestores de empresas ferroviárias, destinada a estabelecer as regras comuns a serem seguidas pelos membros no que diz respeito a acordos na cobrança das taxas de transporte. A segunda matéria em destaque faz referência à Lei de Consolidação e é comentada por gestores ferroviários. Sobre a lei, apresentam-se premissas e aspectos positivos, do ponto de vista da proteção quanto à competição, indicando seu caráter de "necessidade".

Como destacado, não observamos substanciais alterações na perspectiva de competição compartilhada entre representantes das empresas ferroviárias, no período entre o término do conflito interno e a construção da primeira ferrovia transcontinental estadunidense. De modo geral, nos quase 4 anos posteriores à Guerra de Secessão permaneceu vigente entre representantes dessas empresas uma dimensão negativa da competição, orientada pela noção de que esta ocasionaria perdas financeiras severas, devendo ser evitada por meio de rotas alternativas, aquisição de outras empresas, mas, principalmente, por meio de acordos comerciais.

Contudo, ainda que com menor representatividade, pôde-se identificar representações de uma nova concepção da competição entre gestores ferroviários. Entre os anos de 1868 e 1869, observamos argumentações com alternativas para lidar com a competição ferroviária, como alterações nos horários e nas paradas, aumento do nível de conforto dos passageiros, melhorias associadas ao atendimento aos clientes, redução do preço de insumos e até a busca pelo aumento de eficiência na gestão de custos para lidar com a redução de tarifas, decorrentes da concorrência. Béhar (2018) denomina tal concepção perspectiva negativa de consequências positivas. No que se refere a esta, mostra-se subjacente a noção de que a competição, em certo sentido, seria algo inevitável, aquilo que os gestores precisariam enfrentar. Contudo, permaneceria presente uma concepção negativa da competição, decorrente da premissa de que sua existência incorre em perda financeira, aumento da complexidade da gestão, restrições às ações gerenciais e organizacionais.

Associada a tais argumentações, compartilhamos a perspectiva de que a concepção negativa da competição por parte dos gestores ferroviários decorreria, inclusive, do interesse em garantir acesso privilegiado a mercados, proporcionando maior receita financeira e, possivelmente, melhor lucratividade. Em relação aos aspectos contextuais, entendemos uma aproximação à perspectiva clássica da competição, mesmo que a partir de uma concepção contrária à sua ocorrência e até de sua inevitabilidade (especialmente ao final do período em análise). Por inevitabilidade queremos fazer menção à noção da competição enquanto uma força natural, incorrendo em ganhos para a sociedade, a partir de iniciativas individuais (SMITH, 1976; GASTALDI, 2005; BACIC, 2011).

Diante desses pontos, compartilhamos a noção de que estariam presentes componentes de estrutura ideológica proposta por Van Dijk (2015), na construção discursiva por parte dos gestores ferroviários. Reforçados pelo contexto à época, esses componentes se configurariam pela crítica à competição, associada a diversos males para a ação empresarial. A esse respeito, destacamos a polarização discursiva, direcionando as críticas às práticas competitivas (e seus responsáveis) ao exogrupo, ou o "grupo" a ser combatido. Subjacentes ao que se poderia considerar manipulação discursiva estariam os interesses desses gestores e de suas organizações.

No que se refere aos representantes da imprensa, observamos significativa alteração nas concepções compartilhadas a respeito da competição ferroviária, no período em análise. Em um primeiro momento, em período anterior ao conflito, atores da imprensa vinculam a competição ao que Béhar (2018) denomina perspectiva positiva da competição. $O$ autor faz referência à noção de que a (livre) competição ocasionaria benefícios à sociedade, por meio de um equilíbrio justo do 
mercado. Remetendo à perspectiva da Economia Clássica, dentre esses atores também são compartilhadas as noções de que a competição se apresentaria como uma "seleção natural" entre organizações, tendo o sucesso como decorrência da boa capacidade de gestão. Em tal posicionamento também são apresentadas críticas às ações de combate à concorrência por parte dos gestores ferroviários, percebidas como meio para a promoção de ilicitudes e corrupção. Nessa perspectiva, para representantes da imprensa, o Estado deveria atuar como defensor da liberdade competitiva, que ocasionaria ganhos compartilhados socialmente, contra o posicionamento das empresas ferroviárias.

Ainda sob esta perspectiva, observamos os representantes da imprensa questionando as críticas à competição, realizadas por gestores das empresas ferroviárias. No trecho analisado são apresentados argumentos que justificam a queda no transporte ferroviário no ano de 1857, em oposição aos argumentos dos gestores ferroviários, de que a crise teria sido ocasionada pelo excesso de estradas de ferro em concorrência. Nessa crise, os representantes da imprensa destacam a queda da produção agrícola, com consequente redução do tráfego. Tal agente também apresenta um caso de sucesso ocasionado pelo enfrentamento à livre competição, destacado pelo esforço individual. Na referida matéria se destaca a capacidade, a perseverança e o apoio popular à empresa ferroviária nascente. A partir da intepretação compartilhada, nosso entendimento é de que tal perspectiva da competição se mostra alinhada aos ideais presentes na constituição e consolidação da nação estadunidense, como observam Fernandes e Morais (2004) e Ameur (2013). Essa noção também se alinha às práticas econômicas liberais, apontadas à época como adequadas para possibilitar o desenvolvimento humano e tecnológico, pautados pelo crescimento econômico (WEBER, 2006; HOBSBAWM, 2014b). Na concepção ideológica de Van Dijk (2015), nosso entendimento é de que as primeiras impressões apresentadas por agentes da imprensa estariam adequadamente alinhadas às ocorrências do contexto macrossocial, construções ideológicas relacionadas à competição no período (SMITH, 1976; BACIC, 2011). Nesse entendimento, os gestores ferroviários simbolizariam os adversários da perspectiva de avanço social e ampliação do bem comum, consequências da competição na perspectiva da Economia Clássica.

Esse cenário argumentativo, contudo, transforma-se a partir da evolução do conflito armado e da autorização para a construção da primeira ferrovia transcontinental estadunidense (mantendo-se desse modo até a data limite para esta pesquisa - o ano de 1869). Assim, a partir de agosto de 1862, observamos um posicionamento da imprensa contrário à livre competição entre ferrovias, assumindo uma perspectiva negativa da competição. A esta passam a ser associadas adjetivações como "males (da competição)", além do estabelecimento de relações entre a competição entre ferrovias como causa para os resultados desfavoráveis dessas organizações no ano de 1862. No decorrer dos anos em análise, a competição passou a ser denominada, por representantes da imprensa, "ruinosa", "maléfica", "desfavorável", "imprudente" e "prejudicial".

Associada a resultados negativos das empresas ferroviárias, a competição entre ferrovias estadunidenses deveria ser evitada e combatida, ao mesmo tempo que "louros" poderiam ser ocasionados por essas mesmas empresas por meio de rotas nas quais não houvesse competição estabelecida. A guerra civil também é apontada, no discurso da imprensa, enquanto meio favorável de evitar a competição entre empresas ferroviárias, via aumento dos recibos.

Outro aspecto a ser observado e intensamente reforçado se refere à defesa, por parte de interlocutores da imprensa, de acordos, parcerias, fusões e aquisições entre empresas ferroviárias, no sentido evitar a competição via controle de tarifas. Essas ações, destacadas como de "absoluta necessidade" e "sagaz e prudente" possibilitariam a constituição de uma "gigantesca corporação" para fazer frente à competição internacional.

No que se refere a essa dimensão para além das fronteiras nacionais, pôde-se observar, ainda, uma nova concepção de competição compartilhada entre agentes da imprensa: a perspectiva afirmativa da competição (BÉHAR, 2018). Esta se configuraria como uma perspectiva da competição ferroviária voltada ao mercado externo, enquanto meio para afirmação geopolítica diante de outras nações. A construção argumentativa que cerca tal concepção pretenderia afirmar o direito dessa nação de competir internacionalmente diante de outras nações industrializadas, com a finalidade de atingir um novo patamar civilizatório, desenvolvimento e progresso. Diante de tamanha relevância, as ações para competição não deveriam ser pautadas somente pela prática comercial, mas também pela militar, e as ferrovias seriam o meio para tanto (BÉHAR, 2018).

A esse respeito, destacamos a visão apresentada, em matéria jornalística ainda do ano de 1862, de que a cidade de São Francisco seria alçada a uma das "maiores e mais florescentes do mundo", em virtude da ausência competitiva de outros grandes centros urbanos no Oceano Pacífico, como Nova lorque ou Liverpool. O meio para tal façanha passava pela conclusão da ferrovia transcontinental. Nesse mesmo sentido, a extensa malha ferroviária estadunidense é apresentada de modo ufanista e como representação de força, progresso e união diante de outras nações. 
Contudo, é no período entre o término da Guerra de Secessão e a conclusão da Pacific Railroad que a perspectiva afirmativa da competição se mostra mais frequente. A esse respeito, em diversos momentos sendo vinculada ao projeto da ferrovia transcontinental, ganha destaque uma noção de competição que transcende os limites nacionais. Pautada sobre os princípios liberais da Economia Clássica, a uma possibilidade de "supremacia" dos EUA diante de outras nações decorreria, ainda, da possibilidade de acúmulo de riquezas pelas empresas ferroviárias internamente, por meio de acordos e monopólios. A perspectiva afirmativa da competição ganha contornos expansionistas e imperialistas, observada em afirmações como o trecho que critica a ausência de "um mercado estrangeiro para chamar de nosso" ou mesmo pela possibilidade de "crescimento de um magnífico Império no Pacífico".

A partir dessas questões, destacamos a coexistência de duas perspectivas relacionadas à competição ferroviária, compartilhadas entre integrantes da imprensa, a partir do período em que se desenrola o conflito armado. Longe de colocarem-se como contraditórias, elas parecem apresentar visões complementares. Em outras palavras, considerando a possibilidade de competir política e economicamente em nível internacional, decorrente da expansão ferroviária, a extrema competição praticada internamente possibilitaria enfraquecimento das empresas e impossibilidade de atingimento desse "patamar superior". Assim, nossa leitura aponta a noção de que tal objetivo só poderia ser atingido por meio do fortalecimento das empresas ferroviárias estadunidenses, preparando-as para competir além do território nacional. Tal fortalecimento decorreria, necessariamente, da diminuição da competição internamente.

Em nosso entendimento, a representação da concepção ideológica da competição apresentada entre integrantes da imprensa se transforma a partir do desenrolar da Guerra de Secessão. Com a expectativa de competir mundialmente, os gestores ferroviários, antigos "inimigos" (exogrupo), passariam a ser percebidos como parceiros (direcionamento para o endogrupo) na disputa com outras nações (novo exogrupo). Subjacente à construção discursiva, associamos o caráter representativo do progresso e desenvolvimento nacional, decorrente da capacidade competitiva da nação. Essas se apresentariam como as características fundamentais do novo modelo econômico (DOBB, 2012; HOBSBAWM, 2014c), ascendente na Europa a partir do século XVIII (HOBSBAWM, 2014c), e uma das bases constitutivas da sociedade estadunidense (FERNANDES e MORAES, 2004; KARNAL, 2004; AMEUR, 2013). Nesse contexto, as ferrovias eram percebidas como uma das principais demonstrações sociais de capacidade progressista e desenvolvimentista de uma nação (CHANDLER, 1999; PERROW, 2002; WHITE, 2012; WOLMAR, 2012a, 2012b). Em tais aspectos, interpretamos construções discursivas ufanistas por parte dos representantes da imprensa analisados, tendo a ferrovia como meio de atingir tal patamar superior para a sociedade estadunidense. A tal construção associamos um exemplo de componente microssociológico, com a finalidade de ocasionar consequências macrossociológicas (VAN DIJK, 2015), por meio do exercício de poder da mídia. Contudo, não foi possível analisar o impacto de tais elaborações discursivas sobre o contexto macrossocial.

A partir das análises apresentadas, entendemos ter aprofundado as interpretações relativas às concepções de competição do período em análise considerando, inclusive, apreciação por indicativos ideológicos na construção discursiva. No que se refere a tais pontos, também parece possível associar à análise outro aspecto relevante da teoria da ideologia, de Van Dijk (2015): o compartilhamento de valores ideológicos entre grupos sociais específicos ou, na referência ao autor, elaborações de cognição social. Destacadas essas questões, a próxima seção apresenta as considerações finais deste estudo.

\section{CONSIDERAÇÕES FINAIS}

Este estudo teve por objetivo analisar concepções ideológicas da competição no ambiente ferroviário estadunidense no período da Guerra de Secessão e da construção da primeira ferrovia transcontinental, entre 1859 e 1869. Tal proposição se deu a partir de questões centrais, como: a) a relevância das ferrovias estadunidenses na constituição do modelo organizacional contemporâneo, especialmente a partir da Guerra de Secessão; b) o papel das ferrovias enquanto símbolo de modernidade, progresso e desenvolvimento nas sociedades ocidentais do século XIX (CHANDLER, 1999; PERROW, 2002; WOLMAR, 2012a, 2012b; WHITE, 2012); c) a influência dos ideais de justiça, liberdade e ação individual decorrentes da ascensão da classe burguesa na Europa, tendo a competição como aspecto central do novo modelo de sociedade (SMITH, 1976; WEBER, 2006; BACIC, 2011; HOBSBAWM, 2014a, 2014b, 2014c); d) as características específicas da constituição da sociedade estadunidense, a partir do contexto histórico vinculado, destacadas no ponto anterior (KARNAL, 2004; FERNANDES e MORAIS, 2004); d) fragilidade na elaboração conceitual dos EOs, marcada pelo anacronismo e pelas construções orientadas ideologicamente (RAMOS, 1983; TRAGTENBERG, 2005; MATITZ e VIZEU, 2012; BARRETO, 2014; MOURA, 2014; SEIFERT e VIZEU, 2015; BÉHAR, 2019). 
Atrelado ao último aspecto, compartilhamos a perspectiva de que construções discursivas se mostrariam influenciadas por condições sócio-históricas, que enquadram perspectivas subjetivas da realidade, apoiadas em relações de poder (FOUCAULT, 1999, 2008; VAN DIJK, 1990, 2012). Na busca pelo exercício do poder atuariam ideologias sustentadas pelo eixo discurso-cognição-contexto (VAN DIJK, 2006, 2012, 2015). Assim, a partir da realização de uma análise histórica (PIERANTI, 2008; VIZEU, 2010; COSTA, BARROS e MARTINS, 2010), destacamos a possibilidade de investigação do conceito ao longo do tempo, inserido em contextos sociais específicos e dotado de significados também específicos. Desse modo, por meio do uso do Quebra-Cabeças Conceitual Infinito (BÉHAR e FEITOSA, 2019), além do caráter histórico da análise, analisamos construções discursivas de múltiplos atores, na relação com o contexto social. A partir da constituição do corpus, com 128 matérias jornalísticas do American Railroad Journal, procedemos à análise lexical (VAN DIJK, 2006).

Quanto às interpretações decorrentes da análise, divididas entre o discurso dos representantes das empresas ferroviárias e dos representantes da imprensa, pôde-se elaborar entendimentos diferenciados e que apresentariam variação a partir do contexto histórico associado. Relacionada ao discurso apresentado pelos representantes das empresas ferroviárias, destacamos a pouca variação ao longo do período em análise. Em sua maioria, associando a competição entre ferrovias a algo nocivo aos negócios e que, portanto, deveria ser contida por meio de acordos, fusões e aquisições, a visão compartilhada por esses atores sociais destoa do que poderia ser compreendido como bases culturais liberais da nação estadunidense (FERNANDES e MORAIS, 2004; AMEUR, 2013). A representação dessa concepção ideológica residiria na identificação da competição enquanto exogrupo, devendo ser combatida para evitar problemas maiores. A tal caráter associamos os ganhos empresariais decorrentes da falta de competição, especialmente no que se refere ao aumento de ganhos financeiros.

De modo diferente, observamos a transformação na perspectiva de competição ferroviária por parte da imprensa, ao longo do período em análise. Iniciando com uma perspectiva positiva da competição em período anterior ao conflito (em que a livre competição atuaria para a melhoria da eficiência geral do mercado, com ganhos para toda a sociedade), a visão geral compartilhada entre esses atores sociais se modifica com o desenrolar da batalha e a aprovação da primeira ferrovia transcontinental estadunidense. A competição interna entre empresas ferroviárias estadunidenses parece vinculada à perspectiva negativa da competição, ao passo que a possibilidade de competir internacionalmente por meio dessas ferrovias se mostraria acentuada, recebendo a denominação afirmativa da competição. Assim, observamos que as concepções apresentadas no decorrer da análise estariam alinhadas não apenas aos interesses das empresas ferroviárias, mas também (e talvez especialmente) aos interesses do Estado. Contudo, tais interesses parecem variar tanto de acordo com as premissas da Economia Clássica - perspectiva de que os ganhos pudessem ser compartilhados com toda a sociedade estadunidense, ao mesmo tempo que os riscos inerentes a essa "força da natureza" seriam minimizados (GASTALDI, 2005; CARPINTÉRO, 2000; BACIC, 2011) - quanto com a visão compartilhada no contexto internacional em questão - disputas internacionais, inseridas em um ambiente de expansão colonial entre nações industriais, na busca pela supremacia (DOBB, 2012; HOBSBAWM, 2014c).

Às elaborações discursivas observadas entre representantes da imprensa associamos características ideológicas tão distintas quanto as construções argumentativas relacionadas à competição. Assim, no período anterior ao conflito militar, a concepção ideológica da competição apresentada por representantes da imprensa se colocaria alinhada em construções discursivas macrossociais (especialmente as relativas à noção da competição dos economistas clássicos), direcionando críticas aos gestores ferroviários (exogrupo) contrários à livre competição. Contudo, pouco depois do início do conflito bélico, entendemos ocorrer profunda mudança na perspectiva de competição compartilhada por esse agente. A partir desse momento, os gestores ferroviários são percebidos como parte do endogrupo (na tentativa de evitar a competição entre empresas ferroviárias internamente), tendo no exogrupo as demais nações que competiam pelo comércio internacional. Atrelado a tais questões, nosso entendimento é de busca de influência da opinião pública (macrossocial) e partir de um discurso ufanista (microssocial).

Não pretendemos, contudo, apresentar nossas análises de modo definitivo. Assim, no que se refere às limitações do trabalho, destacamos não apenas o caráter de pesquisa histórica realizada em tempo e cultura tão distantes das ocorrências em análise, mas também o restrito uso da fonte documental, que, longe de representar uma generalização de visões, representaria interpretações de um específico e datado recorte social. A estas se somam as limitações inerentes a um estudo de caráter interpretativista, que pressupõe algum nível de interferência do pesquisador na análise. Nesse sentido, convidamos a comunidade acadêmica a contribuir com a pesquisa e o desenvolvimento de perspectivas historicamente orientadas do conceito de competição no âmbito organizacional. Quanto a essa questão, esperamos apontar novas possibilidades de elaboração do conceito e das práticas associadas, de modo a contribuir com a transformação da(s) realidade(s). 


\section{REFERÊNCIAS}

AMEUR, F. Guerra de Secessão. Porto Alegre: L\&PM, 2013.

BACIC, M. J. Gestão de custos: uma abordagem sob o enfoque do processo competitivo e da estratégia empresarial. Curitiba: Juruá, 2011.

BARNEY, J. B.; HESTERLY, W. Economia das organizações: entendendo a relação entre as organizações e a análise econômica. In: HARDY, C.; CLEGG, S. R.; NORD, W. R. (Org.). Handbook de estudos organizacionais. São Paulo: Atlas, 2009. v. 3, p. 131-179.

BARRETO, T. F. Ética ou ideologia empresarial? In: ROCHA, H. CASTRO, R.; VIZEU, A. (Org.). Comunicação e ideologia. Recife: Ed. UFPE, 2014. p. 285-312.

BÉHAR, A. H. Competição organizacional enquanto representação de uma ideologia bélico-militar: o papel da Guerra de Secessão e das ferrovias estadunidenses na construção de um significado. Recife: Ed. UFPE, 2018.

BÉHAR, A. H. Meritocracia enquanto ferramenta da ideologia gerencialista na captura da subjetividade e individualização das relações de trabalho: uma reflexão crítica. Organizações \& Sociedade, v. 26, n. 89, p. 249-268, 2019.

BÉHAR, A. H.; FEITOSA, M. G. G. Contexto histórico, discurso e ideologia na (re)elaboração de conceitos em estudos organizacionais: o método Quebra-Cabeças Conceitual Infinito. In: CONGRESSO BRASILEIRO DE ESTUDOS ORGANIZACIONAIS, 6., 2019, Recife. Anais... Recife: UFPE, 2019.

CARPINTÉRO, J. N. C. Novas técnicas e velhos princípios: competitividade empresarial e formas de gestão. Campinas, SP: Unicamp, 2000.

CHANDLER, A. Strategy and structure: chapters in the history of the industrial enterprise. Cambridge, MA: The MIT Press, 1963.

CHANDLER, A. The visible hand: the managerial revolution in American business. Cambridge, MA/London: The Belknap Press, 1999.

COSTA, A. S. M.; BARROS, D. F.; MARTINS, P. E. M. Perspectiva histórica em administração: novos objetos, novos problemas, novas abordagens. Revista de Administração de Empresas, v. 50, n. 3 , p. 288-299, 2010.

DOBB, M. A evolução do capitalismo. Rio de Janeiro: LTC, 2012.

FERNANDES, L. E.; MORAIS, M. V. Os EUA no século XIX. In: KARNAL, L. et al. História dos Estados Unidos: das origens ao século XXI. São Paulo: Contexto, 2004. e-book.

FOUCAULT, M. As palavras e as coisas. São Paulo: Martins Fontes, 1999.

FOUCAULT, M. A arqueologia do saber. Rio de Janeiro: Forense Universitária, 2008.

GASTALDI, J. P. Elementos de economia política. São Paulo: Saraiva, 2005.

HOBSBAWM, E. J. A era dos impérios, 1875-1914. Rio de Janeiro: Paz e Terra, 2014a.

HOBSBAWM, E. J. A era das revoluções, 1789-1848. Rio de Janeiro: Paz e Terra, 2014b.

HOBSBAWM, E. J. A era do capital, 1848-1875. Rio de Janeiro: Paz e Terra, 2014c.
KARNAL, L. A formação da nação. In: KARNAL, L. et al. História dos Estados Unidos: das origens ao século XXI. São Paulo: Contexto, 2004. e-book.

KOSELLECK, R. Uma história dos conceitos: problema teóricos e práticos. Estudos Históricos, v. 5, n. 10, p. 134-146, 1992.

KOSELLECK, R. Futuro passado: contribuição à semântica dos tempos históricos. Rio de Janeiro: Contraponto: Ed. PUC-Rio, 2006.

MAINGUENEAU, D. Discurso e análise do discurso. In: SIGNORINI, I. (Org.). [Re]discutir texto, gênero e discurso. São Paulo: Parábola, 2008. p. $135-156$

MATITZ, Q. R. S.; VIZEU, F. Construção e uso de conceitos em estudos organizacionais: por uma perspectiva social e histórica. Revista de Administração Pública, Rio de Janeiro, v. 46, n. 2, p. 577-598, 2012.

MOURA, G. Hipergeneralizações: organizações são quase qualquer coisa em best-sellers de introdução à administração. Cadernos EBAPE.BR, Rio de Janeiro, v. 12, n. 1, p. 62-85, 2014.

PERROW, C. Organizing America: wealth, power, and the origins of corporate capitalism. Princeton, NJ: Princeton University Press, 2002.

PIERANTI, O. P. A metodologia historiográfica na pesquisa em administração: uma discussão acerca de princípios e de sua aplicabilidade no Brasil contemporâneo. Cadernos EBAPE.BR, Rio de Janeiro, v. 6, n. 1, p. 1-12, 2008

RAMOS, A. A teoria administrativa e a utilização inadequada de conceitos. Revista de Administração Pública, Rio de Janeiro, v. 17 n. 1, p. 66-76, 1983.

SEIFERT, R. E.; VIZEU, F. Crescimento organizacional: uma ideologia gerencial? Revista de Administração Contemporânea, v. 19, n. 1 , p. 127-141, 2015.

SMITH, A. A riqueza das nações. São Paulo: Nova Cultural, 1976.

TRAGTENBERG, M. Administração, poder e ideologia. São Paulo: Ed. Unesp, 2005.

VAN DIJK, T. A. La noticia como discurso: compreensión, estrutura y producción de la información. Madri: Síntesis, 1990.

VAN DIJK, T. A. Ideologia: una aproximación multidisciplinaria. Barcelona: Gedisa, 2006.

VAN DIJK, T. A. Discurso e poder. São Paulo: Contexto, 2012.

VAN DIJK, T. A. Ideologia. Letras de Hoje, v. 50, s53-s61, 2015. Suplemento.

VIZEU, F. Potencialidades da análise histórica nos estudos organizacionais brasileiros. Revista de Administração de Empresas, v. 50, n. 1, p. 36-46, 2010.

WEBER, M. História geral da economia. São Paulo: Centauro, 2006.

WEBER, M. A ética protestante e o espírito do capitalismo. São Paulo: Martin Claret, 2009.

WHITE, R. Railroaded: the transcontinentals and the making of modern America. New York: W. W. Norton, 2012.

WOLMAR, C. The great railway revolution. London: Atlantic Books, 2012a.

WOLMAR, C. Engines of war: how wars were won \& lost on the railways. London: Atlantic, 2012b. 
Alexandre Hochmann Béhar

ORCID: https://orcid.org/0000-0002-8354-7866

Doutor em Administração; Professor EBTT do eixo Gestão de Negócios, no Instituto Federal de Educação, Ciência e Tecnologia de Pernambuco (IFPE), Campus Paulista, Paulista - PE, Brasil. E-mail: alexandre.behar@paulista.ifpe.edu.br

Doutor em Educação; Professor adjunto do Departamento de Ciências Administrativas da Universidade Federal de Pernambuco (UFPE), Recife - PE, Brasil. E-mail: marcosggfeitosa@gmail.com 